\title{
Effect of TP53 rs1042522 on the susceptibility of patients to oral squamous cell carcinoma and oral leukoplakia: a meta-analysis
}

Zhen Sun $^{1+}$, Wei Gao ${ }^{2+}$ and Jiang-Tao Cui ${ }^{1 *}$

\begin{abstract}
Background: There are different and inconsistent conclusions regarding the genetic relationship between the human tumor suppressor p53 (TP53) rs1042522 polymorphism and the risk of oral squamous cell carcinoma (OSCC) and oral leukoplakia (OL). Therefore, the aim of the study was to comprehensively reassess this association through the performance of an updated meta-analysis.

Methods: After searching the available databases, we systematically screened and included the eligible case-control studies, which contain the full genotype frequency data of the TP53 rs 1042522 polymorphism for both OSCC/OL patients and the negative control groups. $P_{\mathrm{A}}$ ( $P$-value of the association test) and ORs (odd ratios) with their corresponding 95\% Cls (confidence intervals) were calculated to quantitatively evaluate the influence of TP53 rs1042522 on the susceptibility of patients to OSCC or OL.

Results: In total, twenty eligible case-control articles were finally enrolled. Compared with the controls, no increased or decreased risk of OSCC was observed in the cases for six genetic models including allele $C$ vs. $G\left(P_{A}=0.741\right)$, carrier $C$ vs. $\mathrm{G}\left(P_{A}=0.853\right)$, homozygote CC vs. GG $\left(P_{A}=0.085\right)$, heterozygote GC vs. GG $\left(P_{A}=0.882\right)$, dominant $G C+C C$ vs. GG $\left(P_{A}=\right.$ 0.969), and recessive CC vs. GG $+G C\left(P_{A}=0.980\right)$. Furthermore, no statistically significant difference between the cases and controls was detected in most subgroup meta-analyses $\left(P_{A}>0.05\right)$. For the risk of $\mathrm{OL}$, we did not observe the difference between the cases and controls for most genetic models in the overall meta-analysis and subsequent subgroup analysis $\left(P_{A}>0.05\right)$. Begg's test and Egger's test excluded the large risk of publication bias within the included studies in the metaanalysis of OSCC. The sensitivity analysis indicated the above relatively stable results.
\end{abstract}

Conclusions: Our updated meta-analysis (based on the current evidence) shows that TP53 rs1042522 may not confer susceptibility to OSCC. In addition, for the first time, we provided evidence regarding the negative association between TP53 rs1042522 and OL risk.

Keywords: TP53, OSCC, OL, Polymorphism, Meta-analysis

\footnotetext{
* Correspondence: cuijiangt@163.com

†Zhen Sun and Wei Gao contributed equally to this work.

${ }^{1}$ Department of Stomatology, Second Hospital of Tianjin Medical University,

Ping-Jiang Road, He Xi District, 300211 Tianjin, People's Republic of China

Full list of author information is available at the end of the article
}

(c) The Author(s). 2018 Open Access This article is distributed under the terms of the Creative Commons Attribution 4.0 International License (http://creativecommons.org/licenses/by/4.0/), which permits unrestricted use, distribution, and reproduction in any medium, provided you give appropriate credit to the original author(s) and the source, provide a link to the Creative Commons license, and indicate if changes were made. The Creative Commons Public Domain Dedication waiver (http://creativecommons.org/publicdomain/zero/1.0/) applies to the data made available in this article, unless otherwise stated. 


\section{Background}

The human tumor suppressor p53 (TP53) gene on chromosome $17 \mathrm{p} 13$, which is also known as $p 53$, was reported to be involved in a group of cell biology events, such as the cell cycle, apoptosis and genomic stability $[1,2]$. Some genetic variants of the TP53 gene were reported to be linked to human carcinogenesis $[2,3]$. The rs $1042522 \mathrm{G} / \mathrm{C}$, which is a very common polymorphism at exon 4 of the TP53 gene, results in the alteration at codon 72 between arginine (Arg, R) and proline (Pro, P) and causes the TP53Arg72Pro mutation. This may affect the normal function of the TP53 protein and is implicated in susceptibility to several clinical diseases (e.g., colorectal cancer [4], endometriosis [5] or type 2 diabetes [6]).

Herein, we are interested in exploring the potential role of TP53 rs1042522 in the risk of oral squamous cell carcinoma (OSCC) or oral leukoplakia (OL). OSCC, which is the main type of oral cancer, originates from squamous cells on the surface of the oral cavity or oropharynx $[7,8]$. OL is considered the pre-cancerous lesion with white or gray keratosis on the oral mucosa $[8$, 9]. Life style (e.g., tobacco smoking, drinking, and chewing), human papillomavirus (HPV) infection, and other functional variants may be implicated in the etiology of OSCC and OL [7-9].

Currently, the association between rs1042522 of the TP53 gene and OL/OSCC risks has been inconsistently reported among different populations. For instance, TP53 rs1042522 was reported to be associated with the risk of oral potentially malignant disorders (OPMD), including OL, in Argentine patients [10]. However, the risk of OL was not found in Taiwanese patients [11]. TP53 rs1042522 may have been linked to an increased risk of OSCC in an Indian population [12, 13]. However, the negative genetic conclusion between TP53 rs1042522 and OSCC risk in India was also observed in another report [14]. Additionally, the GC genotype of TP53 rs1042522 may be associated with a reduced risk of OSCC patients in Italy [15]. Therefore, the meta-analysis provides helpful insights into the genetic role of TP53 rs1042522 in the susceptibility of the patient to OL or OSCC.

Currently, as far as we know, no meta-analysis has been previously published to investigate the relationship between rs1042522 of the TP53 gene and the predisposition of OL. Regarding the association between TP53 rs1042522 and OSCC risk, only two previous meta-analyses were published [16, 17]. Given the newly published case-control studies and the utilization of a strict screening strategy and quantitative synthesis, we performed an updated meta-analysis aiming to analyze the potential difference of TP53 rs1042522 in the OSCC cases and the negative controls.

\section{Materials and methods}

\section{Database searching}

Our study was conducted in accordance with PRISMA (preferred reporting items for systematic reviews and meta-analyses) guidelines [18]. The PRISMA 2009 checklist is shown in the Additional file 1. Three online databases, including PUBMED, WOS (Web of Science), and EMBASE (Excerpta Medica Database), were searched up to June 2018 without any restrictions regarding language or the publication period. The principle of PICOS, namely, "population" (P), "intervention" (I), "comparator" (C), "outcomes" (O), and "study designs" (S), was considered. A series of terms regarding "population" (human patients with OSCC or OL disease) and "intervention" (polymorphism of the TP53 gene) was utilized. To prevent the excessive filtering of articles, we checked the information of the "comparator" (negative control), "outcomes" (risk of OSCC or OL) and "study designs" (case-control study) by reading the text of the articles without a specific limitation in the electronic database search. The detailed search terms are shown in Additional file 2. Then, we removed the duplicates by using the "Find Duplicates" function of Endnote X7 software (Thomson Reuters, Philadelphia, PA, USA).

\section{Inclusion and exclusion criteria}

With reference to our inclusion and exclusion criteria, two authors (ZS and WG) independently screened and assessed the articles for eligibility based on the PICOS strategy. The inclusion criteria were as follows: $(\mathrm{P})$ containing the patients with oral squamous cell carcinoma and oral leukoplakia; (I) focusing on the TP53 rs1042522 polymorphism; (C) containing the negative controls; $(\mathrm{O})$ the completed genotype distribution of GG, GC and CC and can be used for the assessment of OSCC or OL risk under the six genetic models, namely, $C$ vs. $G$ (allele), $C$ vs. G (carrier), CC vs. GG (homozygote), GC vs. GG (heterozygote), $\mathrm{GC}+\mathrm{CC}$ vs. GG (dominant), and CC vs. GG + GC (recessive); and (S) case-control studies.

The exclusion criteria were as follows: $(\mathrm{P})$ animal or cell data, other disease or unconfirmed OSCC; (I) other genes, other variants or unconfirmed TP53 mutation site; (C) lack of a control group or the genotype distributions of the control deviated from the HWE (Hardy-Weinberg Equilibrium) ( $P$-value of HWE from $\chi^{2}$ test $<$ 0.05); (O) lack of full genotype frequency data in both the case and control group; and (S) a meta-analysis, review, and meeting abstracts.

\section{Data collection and quality assessment}

Then, we carefully extracted the data and listed the basic information (such as method, age, gender, smoking, alcohol, location, ethnicity, and disease type) and genotype frequency in the Tables. E-mails were sent for the 
missing data. We also evaluated the quality of each study using the NOS (Newcastle-Ottawa quality assessment Scale) system with the score of $1 \sim 9$. The high quality was considered when the NOS score was larger than five. A full discussion was required for a conflicting or controversial issue during quality assessment.

\section{Association and heterogeneity test}

STATA 12.0 software (Stata Corporation, Texas, USA) was used for the quantitative synthesis and outcome measures. A two-sided $P$-value of association test, pooled ORs (odd ratios), and the 95\% CI (confidence interval) were performed and used under the following six genetic models: C vs. G (allele); C vs. G (carrier); CC vs. GG (homozygote); GC vs. GG (heterozygote); GC + $\mathrm{CC}$ vs. GG (dominant); and CC vs. GG + GC (recessive). When $P<0.05$ from the association test and the OR value $>1$, the C minor allele of TP53 rs1042522 will be considered the risk factor of OSCC or OL.

We performed the $\mathrm{Q}$ statistic and $\mathrm{I}^{2}$ test to assess the between study heterogeneity. A random-effect model (DerSimonian and Laird method) for high heterogeneity will be used when $P$-values of the $\mathrm{Q}$ statistic are $<0.05$ or the $\mathrm{I}^{2}$ values are $>50 \%$. Otherwise, a fixed-effect model (Mantel-Haenszel method) was used.

Additionally, we performed a group of subgroup analyses based on the control source (population-based or hospital-based), ethnicity (Caucasian or Asian), location (India, USA, China), and OSCC type (oral cavity, HPV16 -/+).

\section{Publication bias}

Taking into consideration that publication bias may exist, Begg's test and Egger's test were conducted when at least ten case-control studies were enrolled. Publication bias was indicated by a $P$ value for Begg's test and Egger's test being less than 0.05 .

\section{Sensitivity analysis}

We also conducted the sensitivity analyses under all of the genetic models. If there is no obvious change for the value of recalculated ORs (odd ratios), and the 95\% CI (confidence interval) when the individual study was systematically omitted at a time, statistical stability of data was considered. The deleted case-control studies, which

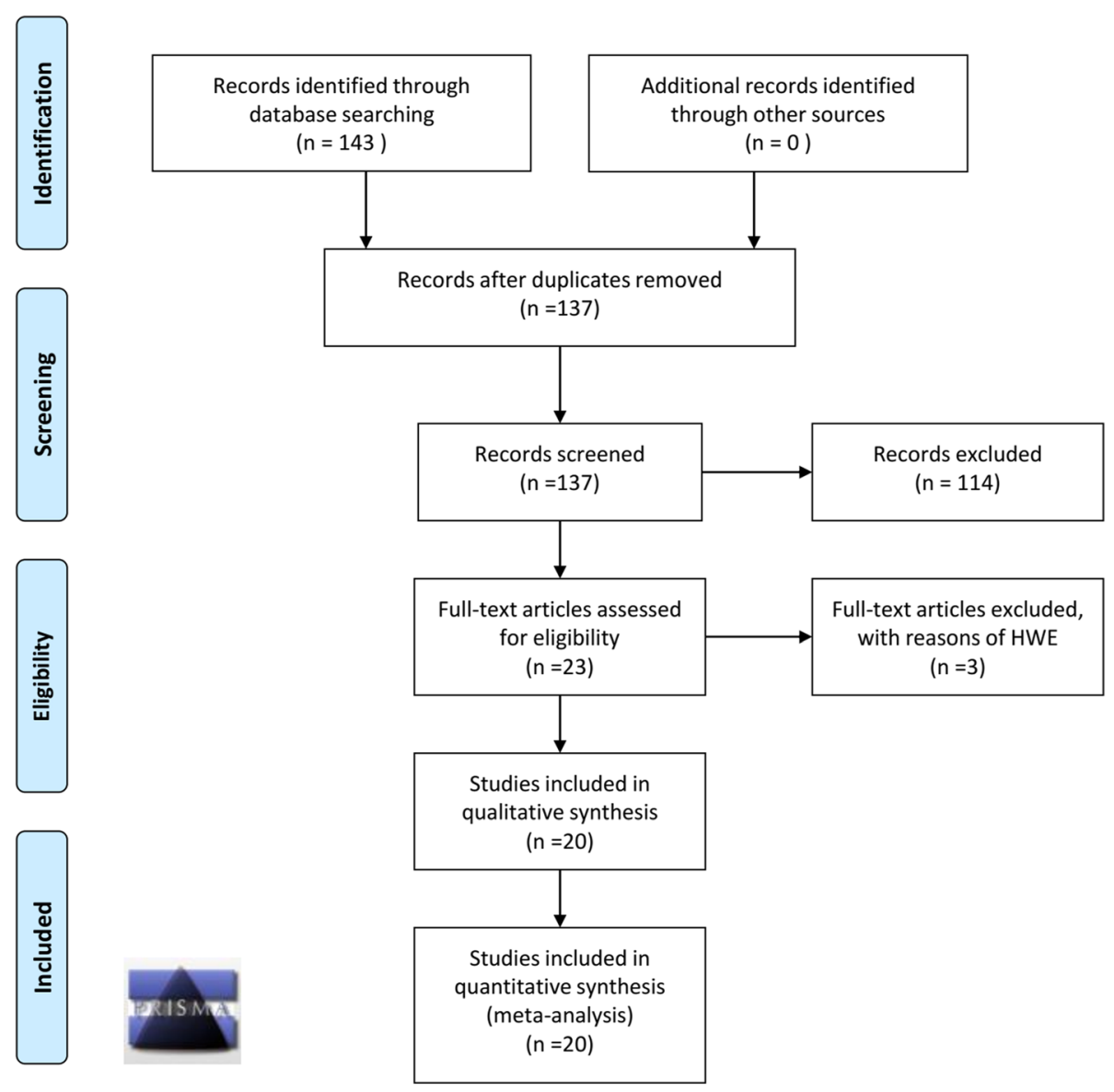

Fig. 1 The PRISMA 2009 flow diagram of our study 


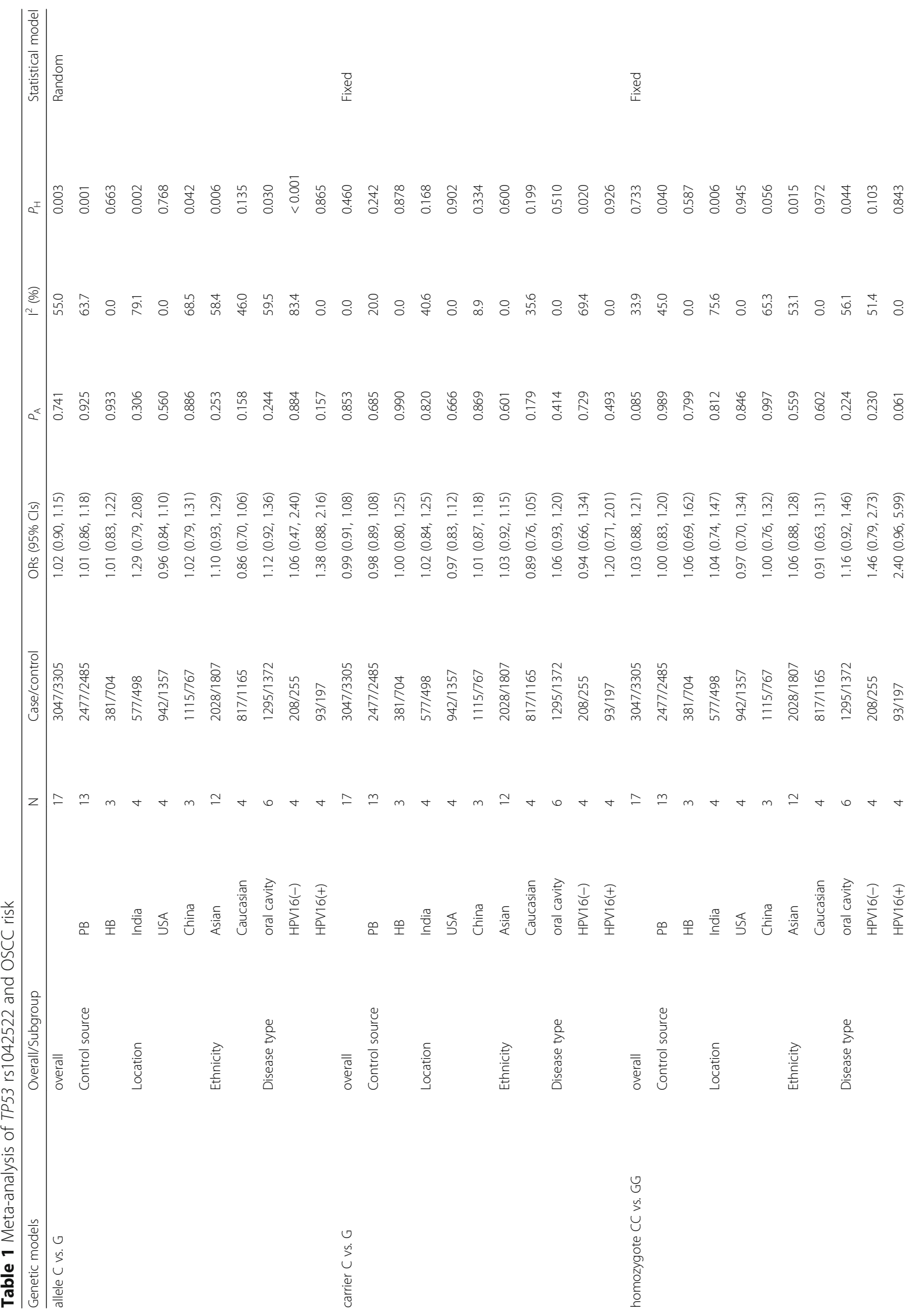




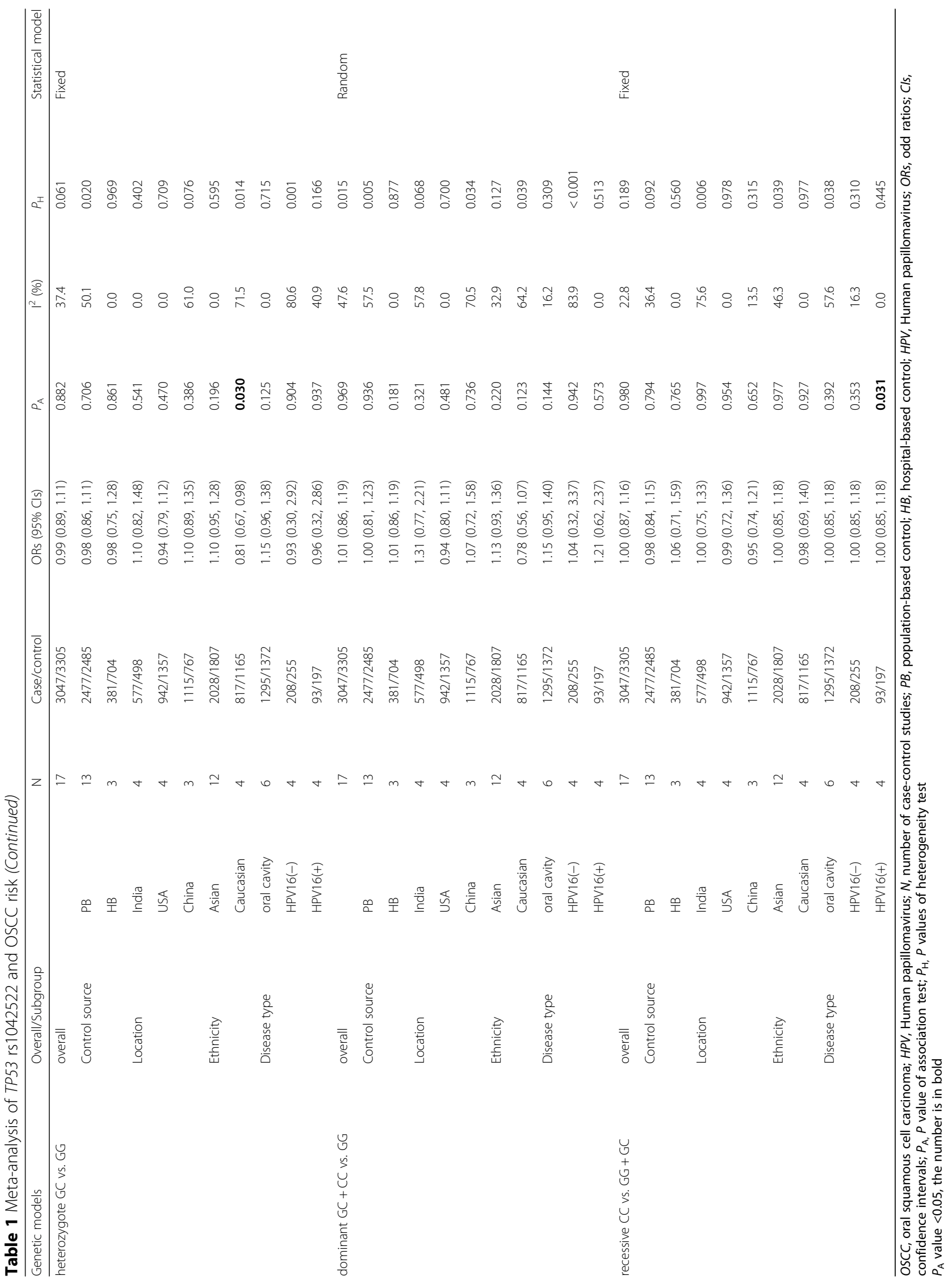


lead to an obvious change, will be regarded as the source of heterogeneity and will be removed.

\section{Results}

\section{Study selection and characteristics}

Figure 1 shows the PRISMA 2009 flow diagram of our study. We obtained 143 records across three databases, including PUBMED $(n=31)$, WOS $(n=84)$ and EMBASE $(n=28)$. Then, a total of 137 records were screened after the duplicates were removed. After screening the titles and abstracts, 114 records were excluded for various reasons: animal or cell data, other disease or unconfirmed OSCC $(n=31)$; other genes, other variants or an unconfirmed TP53 mutation site $(n=35)$; lack of a control group or full genotype frequency data in both the case and the control group $(n=21)$; metaanalysis, review, and meeting abstracts $(n=27)$. Next, the eligibility of 23 full-text articles was evaluated. From these articles, the genotype distributions of three articles did not adhere to HWE. Finally, a total of twenty articles were rigorously included in our quantitative synthesis. Of these twenty articles, sixteen studies [11-15, 19-29] examined oral squamous cell carcinoma (OSCC), and five studies $[10,11,30-32]$ examined oral leukoplakia (OL). The basic information and genotype frequency of the included studies are listed in Additional file 3 and
Additional file 4. NOS assessment system data (Additional file 5) showed that all of the enrolled case-control studies are high quality because all NOS quality scores were larger than five.

\section{TP53 rs1042522 and OSCC risk}

First, a total of 17 case-control studies from 16 articles with 3047 cases and 3305 controls were recruited for the meta-analysis of TP53 rs1042522 and OSCC risk. Table 1 shows the heterogeneity for the three genetic models: allele $\mathrm{C}$ vs. $\mathrm{G}\left[\mathrm{I}^{2}=55.0 \%, P_{\mathrm{H}}(P\right.$-value of heterogeneity $=0.003)$ and dominant $\mathrm{GC}+\mathrm{CC}$ vs. GG $\left(\mathrm{I}^{2}=47.6 \%, P_{\mathrm{H}}=0.015\right)$, which led to the use of a random-effects model (DerSimonian and Laird method). A fixed-effects model (Mantel-Haenszel method) was utilized for others. The summary data in Table 1 show that compared with the controls, no increased or decreased risk of OSCC was observed in the cases for the six genetic models including allele $\mathrm{C}$ vs. $\mathrm{G}\left[P_{A}(P\right.$-value of association test $)=0.741]$, carrier $C$ vs. $\mathrm{G}\left(P_{A}=0.853\right)$, homozygote $\mathrm{CC}$ vs. GG $\left(P_{A}=0.085\right)$, heterozygote GC vs. GG $\left(P_{A}=0.882\right)$, dominant $\mathrm{GC}+\mathrm{CC}$ vs. $\mathrm{GG}\left(P_{A}=0.969\right)$, and recessive $\mathrm{CC}$ vs. $\mathrm{GG}+\mathrm{GC}\left(P_{A}=0.980\right)$. Forest plot data of the allele $\mathrm{C}$ vs. $\mathrm{G}$ model are depicted in Fig. 2.

Subgroup meta-analyses were also performed by $\mathrm{PB}$ (population-based)/HB (hospital-based), Caucasian/Asian, India/USA/China, and oral cavity/HPV16 (-)/HPV16(+).

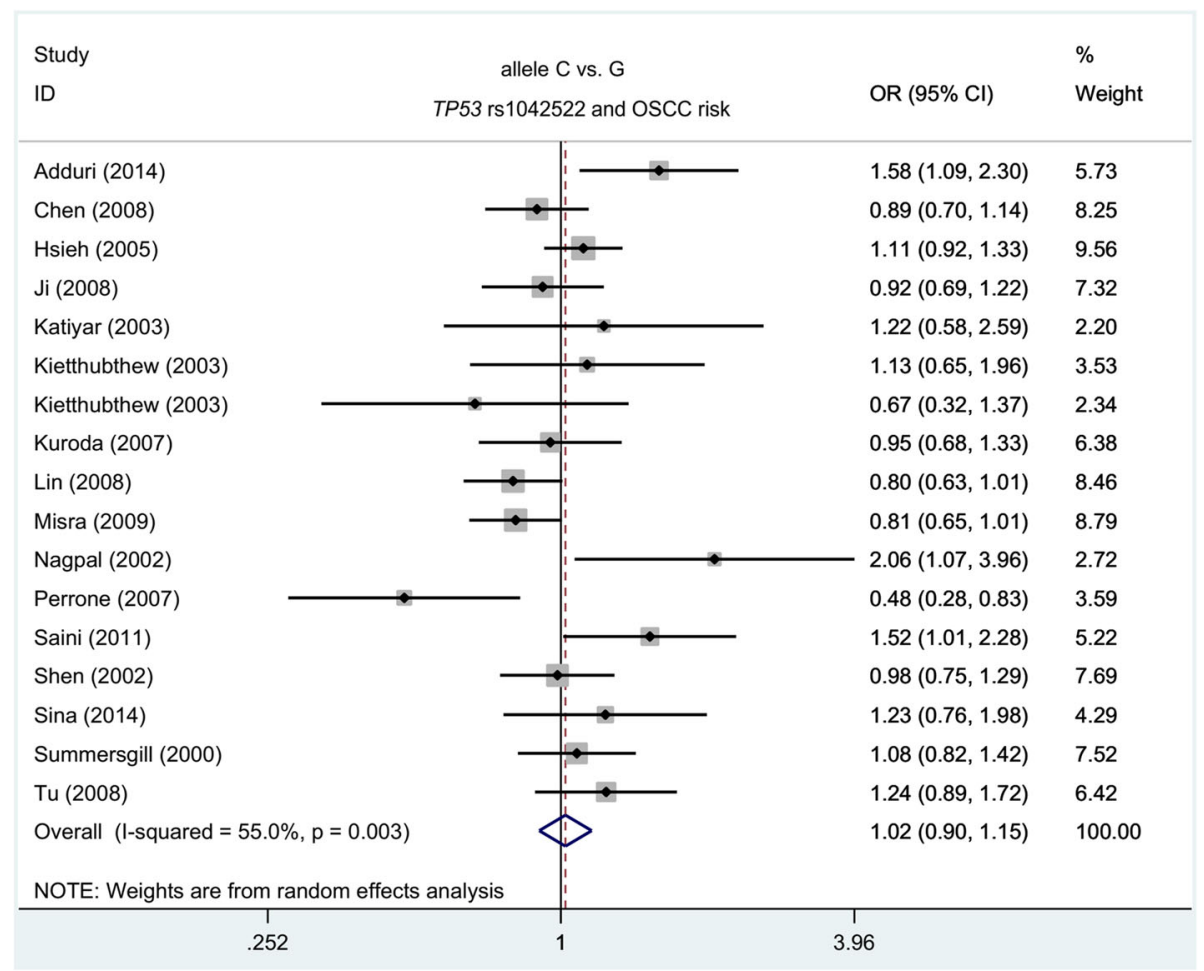

Fig. 2 Meta-analysis (allele C vs. G) of TP53 rs1042522 and OSCC risk 


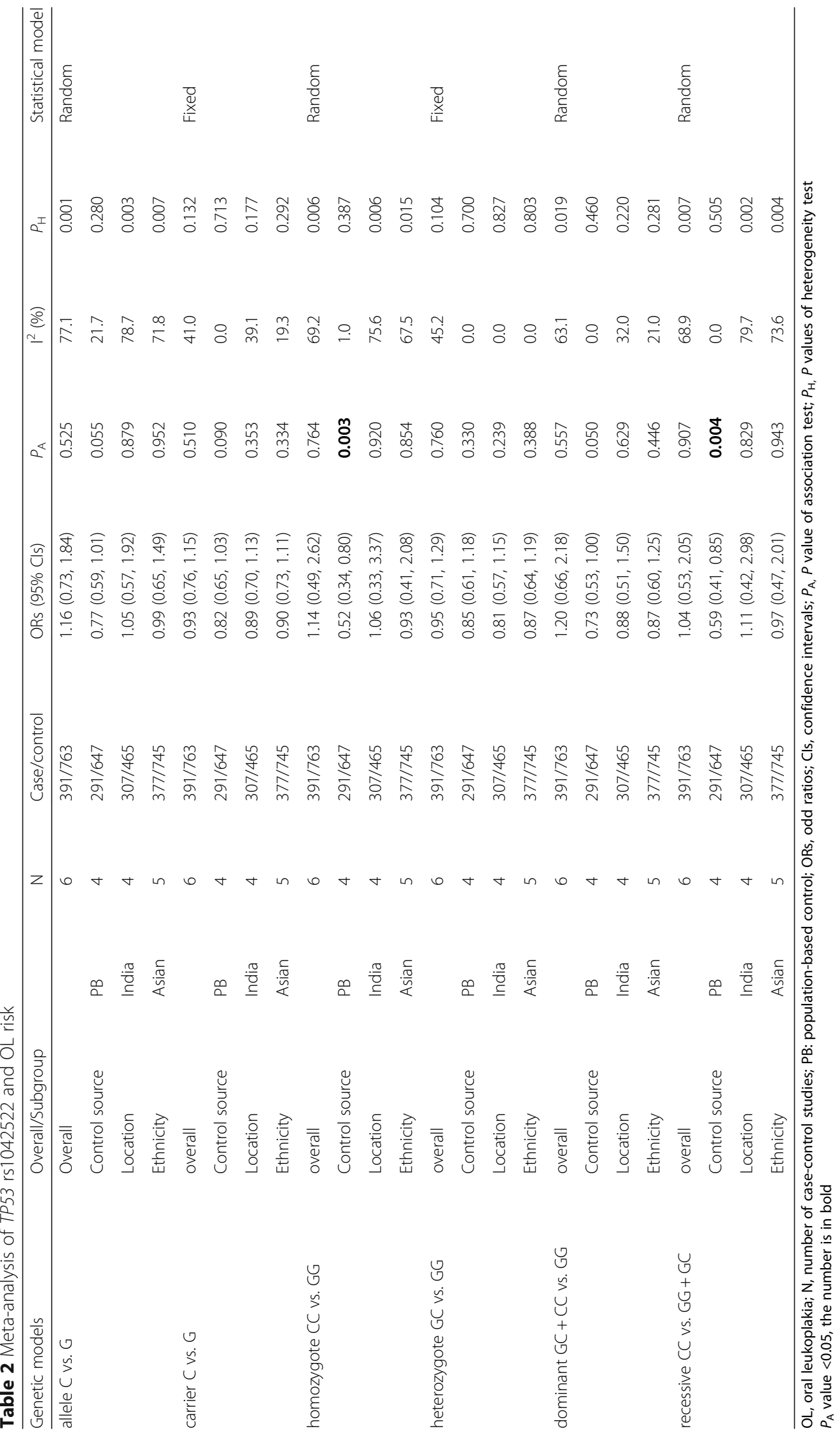


As shown in Table 1 and Additional file 6, Additional file 7, Additional file 8, Additional file 9, there is no statistically significant difference between the cases and the controls in all of the subgroup analyses (all $P_{A}>0.05$ ) except for the Caucasian subgroup for the heterozygote model $\left(P_{\mathrm{A}}=0.030\right)$ and the HPV16(+) subgroup for the recessive model $\left(P_{A}=0.031\right)$. These results indicate that TP53 rs1042522 may have no significant influence on the risk of oral squamous cell carcinoma.

\section{TP53 rs1042522 and OL risk}

Six case-control studies with 391 cases and 763 controls were included from five articles for the meta-analysis of TP53 rs1042522 and OL risk. As shown in Table 2, a fixed-effects model (Mantel-Haenszel method) was used for the carrier $\left(\mathrm{I}^{2}=41.0 \%, P_{\mathrm{H}}=0.132\right)$ and heterozygote $\left(\mathrm{I}^{2}=45.2 \%, P_{\mathrm{H}}=0.104\right)$ models, whereas a random-effects model (DerSimonian and Laird method) was used for the other alleles $\left(\mathrm{I}^{2}>50.0 \%\right)$. We did not detect a difference between the cases and the controls for all of the genetic models in the overall meta-analysis (Table 2, $P_{A}>0.05$ ). After stratification by $\mathrm{PB}$, India and Asia, similar negative results were detected (Table $2, P_{A}>0.05$ ) and only separate from the homozygote $\left(P_{A}=0.003\right)$ and recessive $\left(P_{A}=0.004\right)$ model of $\mathrm{PB}$ subgroup. The forest plots are illustrated in Fig. 3 and in Additional file 10, Additional file 11, Additional file 12. These findings suggest that TP53 rs1042522 may not be associated with the susceptibility to oral leukoplakia.

\section{Publication bias and sensitivity analysis}

We performed both the Begg's test and Egger's test to qualitatively assess the presence of publication bias. Because no more than ten case-control studies in this meta-analysis examined OL, we only analyzed the publication bias in the meta-analysis of OSCC. As shown in Table 3, the $P$-value of Begg's test and Egger's test was larger than 0.05 for all the above genetic models $\left[P_{B}\right.$ $(P$-value of Begg's test $)>0.05 ; P_{E}$ ( $P$-value of Egger's test $)$ $>0.05]$. The Begg's funnel plot (Fig. 4A) and Egger's publication bias plot (Fig. 4B) of the allele model are shown as an example. Thus, there was no large publication bias in our study.

Moreover, we observed a similar summarized OR value in our sensitivity analysis (Fig. 5 for the allele model of OSCC; Additional file 13 for the allele model of OL; and other data not shown), which indicated the reliability of our results.

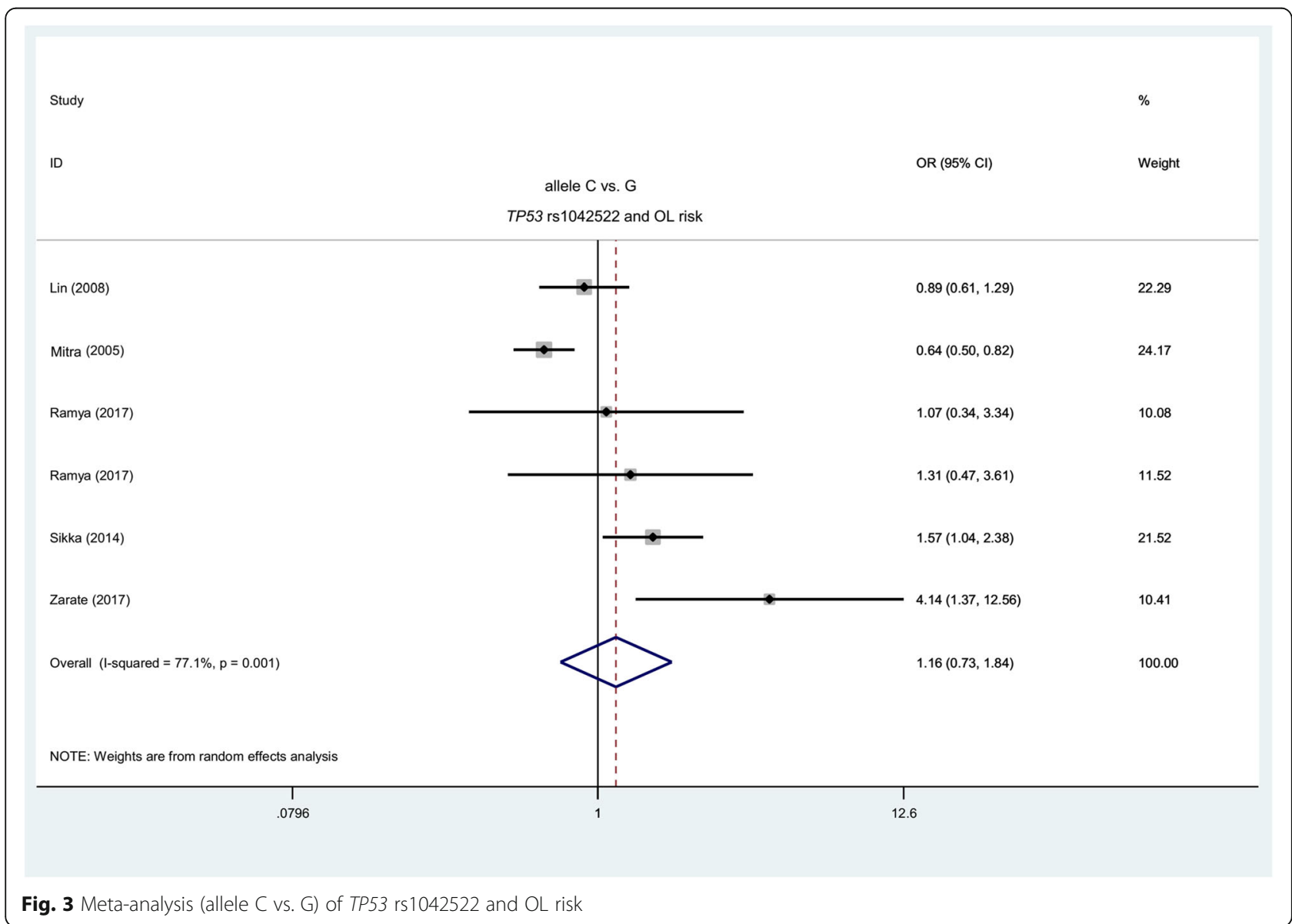


Table 3 Publication bias evaluation

\begin{tabular}{llllll}
\hline Genetic models & \multicolumn{2}{l}{ Begg's test* } & & \multicolumn{2}{l}{ Egger's test } \\
\cline { 2 - 3 } & z & $P_{B}$ & & $t$ & $P_{E}$ \\
\hline allele C vs. G & 1.03 & 0.303 & & 0.88 & 0.393 \\
carrier C vs. G & 0.78 & 0.434 & & 0.52 & 0.609 \\
homozygote CC vs. GG & 0.78 & 0.434 & & 1.51 & 0.152 \\
heterozygote GC vs. GG & 0.95 & 0.343 & & 0.19 & 0.856 \\
dominant GC + CC vs. GG & 0.78 & 0.434 & & 0.69 & 0.504 \\
recessive CC vs. GG + GC & 0.87 & 0.387 & & 1.63 & 0.124
\end{tabular}

"continuity corrected; OSCC, oral squamous cell carcinoma;

$O L$, oral leukoplakia; $P_{B}, P$ value of Begg's test; $P_{E}, P$ value of Egger's test

\section{Discussion}

In this study, we focused on the potential role of TP53 rs1042522 in the risk of oral squamous cell carcinoma through a meta-analysis of sixteen case-control studies. Overall, the results of the present meta-analysis failed to find any significant association ( $P$-value of the association test $>0.05$ ) between TP53 rs1042522 and the risk of OSCC in either the Asian or Caucasian population. Additionally, the current meta-analysis investigated the potential role of TP53 rs1042522 in oral leukoplakia risk based on all the published articles that were available. The results showed that TP53 rs1042522 may not be a susceptible factor for oral leukoplakia disease.

Our meta-analysis data of OSCC coincides with the results reported earlier [16, 17]. In 2009, Zhou et al. performed the first meta-analysis of nine studies [11, 13, $14,19-21,23,25,28]$ and found that TP53 rs1042522 does not seem to be associated with the risk of OSCC [16]. In 2014, Zeng et al. selected eleven case-control studies $[11,13,19,22,23,26,28,29,33-35]$ for a meta-analysis regarding the role of TP53 rs1042522 in the risk of OSCC risk among the Asian population and reported that TP53 rs1042522 is not linked to the risk of an HPV-negative OSCC patient among Asians [17]. In the present meta-analysis, we worked toward identifying the effect TP53 rs1042522 on the risk of OSCC in not only the Asian population but also the Caucasian
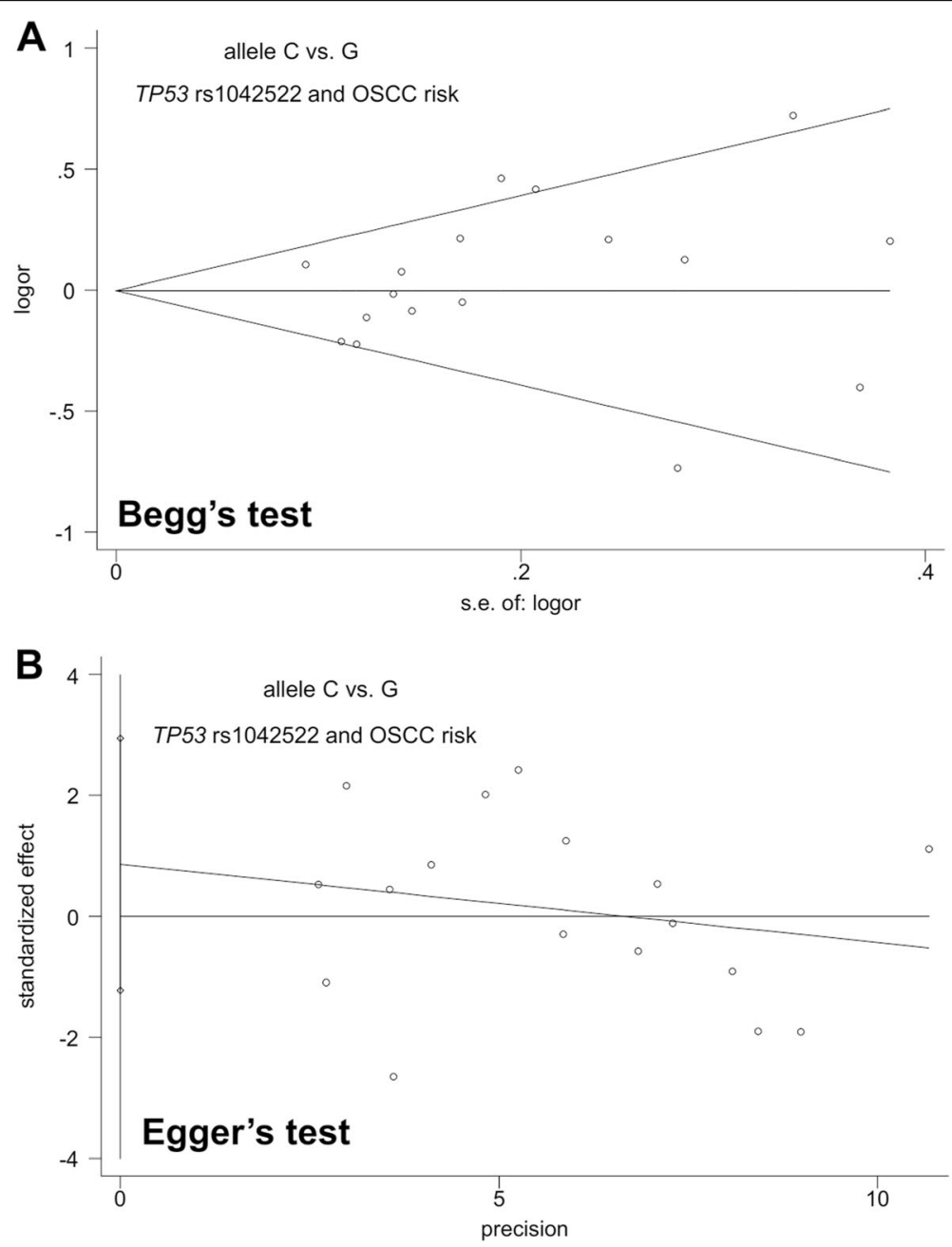

Fig. 4 Publication bias evaluation (allele C vs. G) of TP53 rs1042522 and OSCC risk. (a) Begg's test; (b) Egger's test 


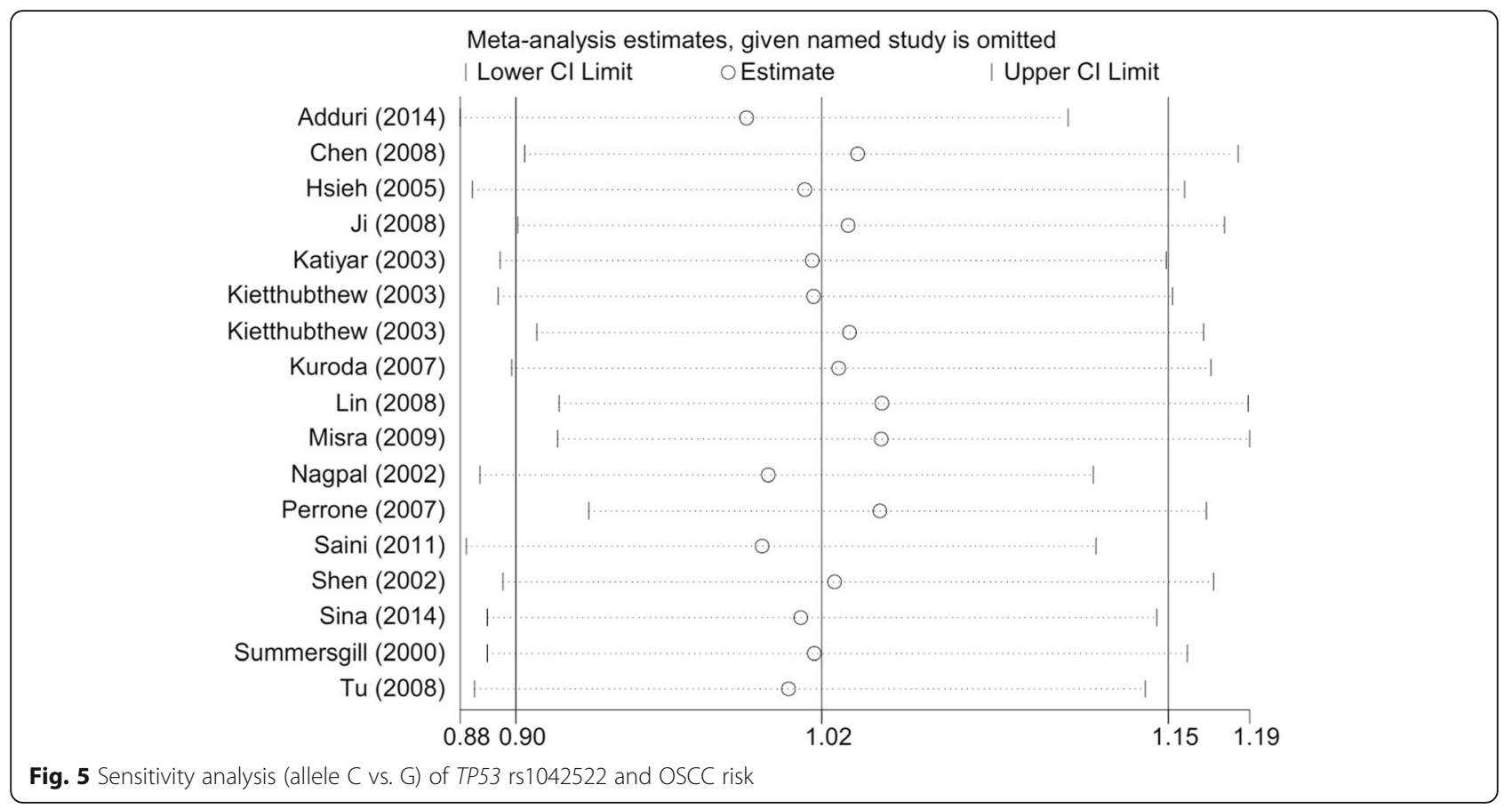

population. We removed one study [33], in which oral cancer was not histopathologically confirmed as SCC, and two other studies [34, 35] for deviation from the Hardy-Weinberg equilibrium. More importantly, we added another eight new case-control studies [12, 14, 15, $20,21,24,25,27]$ in our updated meta-analysis.

Despite the above negative association between TP53 rs1042522 and OSCC risk, different conclusions were observed in meta-analyses regarding the genetic relationship between TP53 rs1042522 and oral cancer risk [36, 37]. In 2013, Jiang et al. identified 17 case-control studies [11, 13, 14, 19-23, 25, 26, 28, 29, 33, 35, 38-40] for a meta-analysis and reported a lack of a genetic link between TP53 rs1042522 and oral cancer risk [36]. However, In 2015, Hou et al. statistically pooled 13 studies [11, $19,20,22-24,26,39,41-45]$ for another meta-analysis of the association between TP53 rs1042522 and oral cancer and revealed that TP53 rs1042522 may be linked to the pathogenesis of oral cancer [37]. Among these included studies, we noted that several case-control studies [33, 39, 40] do not provide the pathological typing information of oral cancer; however, OSCC accounts for most of oral cancer cases. In addition, the genotype distributions of the control group in two studies $[35,38]$ were not in line with Hardy-Weinberg Equilibrium.

Our updated meta-analysis enrolled as much articles as possible. Strict inclusion and exclusion criteria were utilized to select the eligible case-control studies. The reliability of our results was also observed in our sensitivity analysis. However, the limitations still exist in our study. The following concerns should be addressed. (1) Our statistical conclusion should be further verified by more case-control studies with a larger number of subjects. Only six case-control studies from five articles [10, 11, 30-32] were included for the meta-analysis of oral leukoplakia, and only four case-control studies [13-15, 26] were enrolled in the HPV $16+/$ - subgroup meta-analysis of OSCC. We only detected the role of HPV 16 but not any other type of HPV. In addition, we only enrolled four case-control studies $[15,20,21,24]$ for the "non-Asian, Caucasian" subgroup analysis of TP53 rs1042522 and OSCC risk. Furthermore, no case-control study population was obtained for the "Caucasian" subgroup analysis of TP53 rs1042522 and OL risk. (2) The existence of between-study heterogeneity was observed in some comparisons. For example, the high heterogeneity among the case-control studies in the overall meta-analysis of TP53 rs1042522 and OSCC risk under allele and dominant genetic models disappears in the hospital-based, USA and HPV16(+) subgroups. The complexity of OSCC/OL pathogenesis, the source of control, location and ethnicity may be involved in this dynamic. (3) We did not perform the meta-analysis regarding the role of the other loci of the TP53 gene or the variant combination between the TP53 gene and other genes. (4) No case-control study in the Caucasian population was enrolled in the meta-analysis of TP53 rs1042522 and OL risk. In addition, we did not perform Begg's test and Egger's test to assess the risk of publication bias in meta-analysis of OL because the number of included case-control studies was less than ten. Even though our data from Begg's test and Egger's test show no proof of publication bias for the meta-analysis of 
OSCC, we still cannot ignore the impact of publication language, time, and regional variation on the presence of selection bias. (5) Even though the basic information of gender, age, smoking and alcohol consumption was gathered, the relevant stratification analyses by adjusted factors were not performed due to the lack of original genotype frequency data in both the case and control groups.

\section{Conclusions}

In conclusion, according to the currently available case-control studies, our updated meta-analysis data together with previous reports fail to statistically support the genetic relationship between TP53 rs1042522 and the risk of oral squamous cell carcinoma. Additionally, our meta-analysis is the first study to report that the TP53 rs1042522 polymorphism does not appear to confer susceptibility to oral leukoplakia patients. Additional high-quality case-control studies will help us to scientifically assess the significance of the TP53 rs1042522 polymorphism on the risk of oral leukoplakia and oral squamous cell carcinoma.

\section{Additional files}

Additional file 1: PRISMA 2009 checklist. (DOCX 28 kb)

Additional file 2: The terms of the database search. (DOCX $18 \mathrm{~kb}$ )

Additional file 3: Basic information of the included case-control studies. (DOCX $21 \mathrm{~kb}$ )

Additional file 4: Genotype frequency data of the included case-control studies. (DOCX $19 \mathrm{~kb}$ )

Additional file 5: Quality assessment of the included case-control studies. (DOCX $23 \mathrm{~kb}$ )

Additional file 6: Subgroup analysis (allele C vs. G) of OSCC by the control source. (TIF $1495 \mathrm{~kb}$ )

Additional file 7: Subgroup analysis (allele C vs. G) of OSCC by the location. (TIF 1307 kb)

Additional file 8: Subgroup analysis (allele C vs. G) of OSCC by the ethnicity. (TIF $1362 \mathrm{~kb}$ )

Additional file 9: Subgroup analysis (allele C vs. G) of OSCC by the disease type. (TIF $1498 \mathrm{~kb}$ )

Additional file 10: Subgroup analysis (allele C vs. G) of OL by the location. (TIF $1225 \mathrm{~kb}$ )

Additional file 11: Subgroup analysis (allele C vs. G) of OL by the ethnicity. (TIF $1092 \mathrm{~kb}$ )

Additional file 12: Subgroup analysis (allele C vs. G) of OL by the control source. (TIF $1103 \mathrm{~kb}$ )

Additional file 13: Sensitivity analysis (allele C vs. G) of TP53 rs1042522 and $\mathrm{OL}$ risk. (TIF $358 \mathrm{~kb}$ )

\section{Abbreviations}

Cl: confidence interval; Embase: Excerpta Medica Database; HPV: papillomavirus; HWE: Hardy-Weinberg Equilibrium; OL: oral leukoplakia; OPMD: oral potentially malignant disorders; ORs: odd ratios; OSCC: oral squamous cell carcinoma; PRISMA: preferred reporting items for systematic reviews and meta-analyses; TP53: tumor suppressor p53; WOS: Web of Science

\section{Funding}

Not applicable.
Availability of data and materials

All data generated or analyzed during the present study are included in this published article.

\section{Authors' contributions}

ZS designed the study. ZS, WG and JTC extracted, analyzed, and interpreted the data. ZS and JTC drafted the manuscript. All authors read and approved the final version of the manuscript.

Ethics approval and consent to participate

Not applicable.

\section{Consent for publication}

Not applicable.

\section{Competing interests}

The authors declare that they have no competing interests.

\section{Publisher's Note}

Springer Nature remains neutral with regard to jurisdictional claims in published maps and institutional affiliations.

\section{Author details}

'Department of Stomatology, Second Hospital of Tianjin Medical University, Ping-Jiang Road, He Xi District, 300211 Tianjin, People's Republic of China. ${ }^{2}$ Department of Interventional Therapy, Tianjin Medical University Cancer Institute and Hospital, National Clinical Research Center for Cancer, Key Laboratory of Cancer Prevention and Therapy, Tianjin's Clinical Research Center for Cancer, Huan Hu West Road, 300060 Tianjin, People's Republic of China.

Received: 16 February 2018 Accepted: 3 August 2018

Published online: 20 August 2018

\section{References}

1. Isobe M, Emanuel BS, Givol D, Oren M, Croce CM. Localization of gene for human p53 tumour antigen to band 17p13. Nature. 1986:320(6057):84-5.

2. Hanel W, Moll UM. Links between mutant p53 and genomic instability. J Cell Biochem. 2012;113(2):433-9.

3. Merino D, Malkin D. p53 and hereditary cancer. Subcell Biochem. 2014;85:1-16.

4. Tian X, Dai S, Sun J, Jiang S, Jiang Y. The association between the TP53 Arg72Pro polymorphism and colorectal cancer: an updated meta-analysis based on 32 studies. Oncotarget. 2017;8(1):1156-65.

5. Yan Y, Wu R, Li S, He J. Meta-analysis of association between the TP53 Arg72Pro polymorphism and risk of endometriosis based on case-control studies. Eur J Obstet Gynecol Reprod Biol. 2015:189:1-7.

6. Burgdorf KS, Grarup N, Justesen JM, Harder MN, Witte DR, Jorgensen T, et al. Studies of the association of Arg72Pro of tumor suppressor protein p53 with type 2 diabetes in a combined analysis of 55,521 Europeans. PLoS One. 2011;6(1):e15813.

7. Sathiyasekar AC, Chandrasekar P, Pakash A, Kumar KU, Jaishlal MS. Overview of immunology of oral squamous cell carcinoma. J Pharm Bioallied Sci. 2016:8(Suppl 1):S8-s12.

8. Yu CH, Lin HP, Cheng SJ, Sun A, Chen HM. Cryotherapy for oral precancers and cancers. J Formos Med Assoc. 2014:113(5):272-7.

9. Arduino PG, Bagan J, El-Naggar AK, Carrozzo M. Urban legends series: oral leukoplakia. Oral Dis. 2013;19(7):642-59.

10. Zarate AM, Don J, Secchi D, Carrica A, Galindez Costa F, Panico R, et al. Study of the TP53 codon 72 polymorphism in oral cancer and oral potentially malignant disorders in argentine patients. Tumour Biol. 2017; 39(5):1010428317699113.

11. Lin YC, Huang HI, Wang LH, Tsai CC, Lung O, Dai CY, et al. Polymorphisms of COX-2 -765G>C and p53 codon 72 and risks of oral squamous cell carcinoma in a Taiwan population. Oral Oncol. 2008:44(8):798-804.

12. Adduri RSR, Katamoni R, Pandilla R, Madana SN, Paripati AK, Kotapalli V, et al. TP53 Pro72 Allele Is Enriched in Oral Tongue Cancer and Frequently Mutated in Esophageal Cancer in India. PLoS One. 2014:9(12).

13. Nagpal JK, Patnaik S, Das BR. Prevalence of high-risk human papilloma virus types and its association with P53 codon 72 polymorphism in tobacco addicted oral squamous cell carcinoma (OSCC) patients of eastern India. Int J Cancer. 2002;97(5):649-53. 
14. Katiyar S, Thelma BK, Murthy NS, Hedau S, Jain N, Gopalkrishna V, et al. Polymorphism of the p53 codon 72 Arg/pro and the risk of HPV type 16/ 18-associated cervical and oral cancer in India. Mol Cell Biochem. 2003; 252(1-2):117-24

15. Perrone $F$, Mariani L, Pastore E, Orsenigo M, Suardi S, Marcomini B, et al. p53 codon 72 polymorphisms in human papillomavirus-negative and human papillomavirus-positive squamous cell carcinomas of the oropharynx. Cancer. 2007;109(12):2461-5.

16. Zhuo XL, Li Q, Zhou Y, Cai L, Xiang ZL, Yuan W, et al. Study on TP53 codon 72 polymorphisms with oral carcinoma susceptibility. Arch Med Res. 2009; 40(7):625-34.

17. Zeng XT, Luo W, Geng PL, Guo Y, Niu YM, Leng WD. Association between the TP53 codon 72 polymorphism and risk of oral squamous cell carcinoma in Asians: a meta-analysis. BMC Cancer. 2014;14:469.

18. Moher D, Liberati A, Tetzlaff J, Altman DG. Preferred reporting items for systematic reviews and meta-analyses: the PRISMA statement. PLoS Med. 2009;6(7):e1000097.

19. Kuroda Y, Nakao H, Ikemura K, Katoh T. Association between the TP53 codon72 polymorphism and oral cancer risk and prognosis. Oral Oncol. 2007;43(10):1043-8.

20. Chen X, Sturgis EM, El-Naggar AK, Wei Q, Li G. Combined effects of the p53 codon 72 and p73 G4C14-to-A4T14 polymorphisms on the risk of HPV16associated oral cancer in never-smokers. Carcinogenesis. 2008;29(11):2120-5.

21. Shen $H$, Zheng $Y$, Sturgis EM, Spitz MR, Wei Q. P53 codon 72 polymorphism and risk of squamous cell carcinoma of the head and neck: a case-control study. Cancer Lett. 2002;183(2):123-30.

22. Misra C, Majumder M, Bajaj S, Ghosh S, Roy B, Roychoudhury S. Polymorphisms at p53, p73, and MDM2 loci modulate the risk of tobacco associated leukoplakia and oral cancer. Mol Carcinog. 2009:48(9):790-800.

23. Tu HF, Chen HW, Kao SY, Lin SC, Liu CJ, Chang KW. MDM2 SNP 309 and p53 codon 72 polymorphisms are associated with the outcome of oral carcinoma patients receiving postoperative irradiation. Radiother Oncol. 2008;87(2):243-52.

24. Ji X, Neumann AS, Sturgis EM, Adler-Storthz K, Dahlstrom KR, Schiller JT, et al. p53 codon 72 polymorphism associated with risk of human papillomavirus-associated squamous cell carcinoma of the oropharynx in never-smokers. Carcinogenesis. 2008;29(4):875-9.

25. Summersgill KF, Smith EM, Kirchner HL, Haugen TH, Turek LP. p53 polymorphism, human papillomavirus infection in the oral cavity, and oral cancer. Oral Surg Oral Med Oral Pathol Oral Radiol Endod. 2000;90(3):334-9.

26. Saini R, Tang TH, Zain RB, Cheong SC, Musa Kl, Saini D, et al. Significant association of high-risk human papillomavirus (HPV) but not of p53 polymorphisms with oral squamous cell carcinomas in Malaysia. J Cancer Res Clin Oncol. 2011;137(2):311-20.

27. Sina M, Pedram M, Ghojazadeh M, Kochaki A, Aghbali A. P53 gene codon 72 polymorphism in patients with oral squamous cell carcinoma in the population of northern Iran. Med Oral Patol Oral Cir Bucal. 2014;19(6):e550-5.

28. Hsieh LL, Huang TH, Chen $\mathrm{H}$, Liao CT, Wang HM, Lai CH, et al. p53 polymorphisms associated with mutations in and loss of heterozygosity of the p53 gene in male oral squamous cell carcinomas in Taiwan. Br J Cancer. 2005;92(1):30-5.

29. Kietthubthew S, Sriplung H, Au WW, Ishida T. The p53 codon 72 polymorphism and risk of oral cancer in southern Thailand. Asian Pac J Cancer Prev. 2003:4(3):209-14.

30. Mitra S, Sikdar N, Misra C, Gupta S, Paul RR, Roy B, et al. Risk assessment of p53 genotypes and haplotypes in tobacco-associated leukoplakia and oral cancer patients from eastern Idia. Int J Cancer. 2005;117(5):786-93.

31. Ramya AS, Majumdar S, Babu TM, Uppala D, Srinivas B, Rao AK. Expression of human papillomavirus DNA and p53 polymorphisms through polymerase chain reaction in normal mucosa and oral leukoplakia individuals with deleterious oral habits. Int J Appl Basic Med Res. 2017;7(2):134-8.

32. Sikka S, Sikka P. Association of Human Papilloma Virus 16 infection and p53 polymorphism among tobacco using oral leukoplakia patients: a Clinicopathologic and genotypic study. Int J Prev Med. 2014;5(4):430-8.

33. Bau DT, Tsai MH, Lo YL, Hsu CM, Tsai Y, Lee CC, et al. Association of p53 and p21(CDKN1A/WAF1/CIP1) polymorphisms with oral cancer in Taiwan patients. Anticancer Res. 2007;27(3b):1559-64.

34. Saleem S, Azhar A, Hameed A, Khan MA, Abbasi ZA, Qureshi NR, et al. P53 (Pro72Arg) polymorphism associated with the risk of oral squamous cell carcinoma in gutka, niswar and manpuri addicted patients of Pakistan. Oral Oncol. 2013;49(8):818-23.
35. Tandle AT, Sanghvi V, Saranath D. Determination of p53 genotypes in oral cancer patients from India. Br J Cancer. 2001;84(6):739-42.

36. Jiang N, Pan J, Wang L, Duan YZ. No significant association between p53 codon 72 Arg/pro polymorphism and risk of oral cancer. Tumour Biol. 2013; 34(1):587-96.

37. Hou J, Gu Y, Hou W, Wu S, Lou Y, Yang W, et al. P53 codon 72 polymorphism, human papillomavirus infection, and their interaction to oral carcinoma susceptibility. BMC Genet. 2015;16:72.

38. Drummond SN, De Marco L, Pordeus Ide A, Barbosa AA, Gomez RS. TP53 codon 72 polymorphism in oral squamous cell carcinoma. Anticancer Res. 2002:22(6a):3379-81.

39. Ihsan R, Devi TR, Yadav DS, Mishra AK, Sharma J, Zomawia E, et al Investigation on the role of p53 codon 72 polymorphism and interactions with tobacco, betel quid, and alcohol in susceptibility to cancers in a highrisk population from north East India. DNA Cell Biol. 2011;30(3):163-71.

40. Jing G, Lv K, Jiao X. The p53 codon 72 polymorphism and the risk of oral Cancer in a Chinese Han population. Genetic Testing and Molecular Biomarkers. 2012;16(9):1149-52.

41. Kitkumthorn N, Yanatatsaneejit P, Rabalert J, Dhammawipark C, Mutirangura A. Association of P53 codon 72 polymorphism and ameloblastoma. Oral Dis. 2010;16(7):631-5.

42. Patel KR, Vajaria BN, Begum R, Shah FD, Patel JB, Shukla SN, et al. Association between p53 gene variants and oral cancer susceptibility in population from Gujarat, West India. Asian Pac J Cancer Prev. 2013;14(2): 1093-100.

43. Storey A, Thomas M, Kalita A, Harwood C, Gardiol D, Mantovani F, et al. Role of a p53 polymorphism in the development of human papillomavirusassociated cancer. Nature. 1998;393(6682):229-34.

44. Wang Z, Sturgis EM, Zhang Y, Huang Z, Zhou Q, Wei Q, et al. Combined p53-related genetic variants together with HPV infection increase oral cancer risk. Int J Cancer. 2012;131(3):E251-8.

45. Zemleduch T, Lianeri M, Rydzanicz M, Gajecka M, Szyfter K, Jagodzinski PP. Contribution of polymorphism in codon 72 of TP53 gene to laryngeal cancer in polish patients. Oral Oncol. 2009;45(8):683-6.
Ready to submit your research? Choose BMC and benefit from:

- fast, convenient online submission

- thorough peer review by experienced researchers in your field

- rapid publication on acceptance

- support for research data, including large and complex data types

- gold Open Access which fosters wider collaboration and increased citations

- maximum visibility for your research: over $100 \mathrm{M}$ website views per year

At $\mathrm{BMC}$, research is always in progress.

Learn more biomedcentral.com/submissions 